\title{
Valproate for acute mania reduced neuroleptic administration and improved symptoms on mania and global function scales
}

Müller-Oerlinghausen B, Retzow A, Henn FA, et al, for the European Valproate Mania Study Group. Valproate as an adjunct to neuroleptic medication for the treatment of acute episodes of mania: a prospective, randomized, double-blind, placebo-controlled, multicenter study. J Clin Psychopharmacol 2000 Apr;20:195-203.

\section{Question}

In patients with acute mania, does the addition of valproate to neuroleptic agents increase efficacy and reduce the neuroleptic dose?

\section{Design}

21 day randomised \{allocation concealed*\}†, blinded \{clinicians, patients, outcome assessors, and statisticians $\}\}^{*}$, placebo controlled trial.

\section{Setting}

\{State mental hospitals and university psychiatric hospitals $\} \uparrow(10$ in Germany and 8 in central and eastern Europe).

\section{Patients}

136 patients who were 18-65 years of age (mean age $38 \mathrm{y}, 57 \%$ women) and were admitted to hospital for acute episodes of mania. Exclusion criteria included suspected mania of exogenous genesis, lithium and/or carbamazepine prophylaxis at study entry, hypersensitivity or contraindication to study drugs, severe system diseases, and forensic hospital admission. $87 \%$ of patients completed the study.

\section{Intervention}

Patients were allocated to valproate, $20 \mathrm{mg} / \mathrm{kg}$ of body weight in 3 doses per day $(n=69$, mean dose 19.6 $\mathrm{mg} / \mathrm{kg}$ ) or placebo $(\mathrm{n}=67)$. Patients also received standard neuroleptics (haloperidol and/or perazine). Clinicians adjusted the neuroleptic dose to the lowest essential dose.

\section{Main outcome measures}

Change in mean neuroleptic dose. Secondary outcomes were scores on the Young Mania Rating Scale (YMRS), Clinical Global Impression Scale (CGI), and the Global Assessment Scale (GAS).

\section{Main results}

Analysis was by intention to treat. After adjusting for baseline differences, the mean daily dose of neuroleptics was lower in the valproate group than the placebo group for weeks 2 and 3 (mean dose at week 3 [haloperidol equivalent] $8.2 \mathrm{mg} / \mathrm{d}$ v $9.3 \mathrm{mg} / \mathrm{d}$, $\mathrm{p}<0.001$ ). More patients in the valproate group than in the placebo group were responders on the YMRS (defined as a $\geqslant 50 \%$ reduction in scores) $(\mathrm{p}=0.005)$ and the CGI (defined as moderate or marked improvement) $(p=0.007)$ (table). Valproate led to greater improvement on the GAS than did placebo (difference in mean change $8.3, \mathrm{p}=0.01$ ).

\section{Conclusion}

In patients admitted to hospital for acute mania, the addition of valproate to neuroleptic agents was more efficacious than placebo or neuroleptic agents and reduced the required dose of neuroleptic medication.

*See glossary.

$\dagger$ Information provided by author.

Source of funding: Desitin Arzneimittel GmbH, Hamburg, Germany.

For correspondence: $\operatorname{Dr} B$

Müller-Oerlinghausen, Research Group

Clinical

Psychopharmacology, Department of

Psychiatry, Freie Universität Berlin, Eschenallee 3, D-14050 Berlin, Germany. Fax +4930 84458797.

Valproate $v$ placebo added to neuroleptic medication for acute mania:

\begin{tabular}{|c|c|c|c|c|}
\hline Outcomes at 21 days & Valproate & Placebo & RBI $(95 \%$ Cl) & NNT (Cl) \\
\hline$\geqslant 50 \%$ improvement on the YMRS & $70 \%$ & $46 \%$ & $50 \%(12$ to 106$)$ & 5 (3 to 15$)$ \\
\hline $\begin{array}{l}\text { Moderate to marked improvement } \\
\text { on the CGI }\end{array}$ & $68 \%$ & $50 \%$ & $36 \%$ (2 to 85$)$ & 6 (4 to 74$)$ \\
\hline
\end{tabular}

¥YMRS = Young Mania Rating Scale; CGI = Clinical Global Impression Scale. Other abbreviations defined in glossary; RBI, NNT, and $\mathrm{Cl}$ calculated from data in article.

\section{COMMENTARY}

Neuroleptics are often used to treat manic episodes despite the lack of research comparing these drugs with other potentially better tolerated treatments. ${ }^{1}$ Regardless of clinical status and despite long term risks, this treatment is usually continued after stabilisation. ${ }^{2}$ Placebo controlled trials, which are used to establish efficacy, preclude the participation of more severely ill patients and thereby reduce the generalisability of many treatment study results.

In this study by Müller-Oerlinghausen et al, all patients were treated with conventional neuroleptics, usually haloperidol. This improves generalisability because more severely ill patients could enter. The study design therefore mirrors a practical treatment decision. The regimen of valproate can produce rapid response in patients with psychotic mania. ${ }^{3}$ The design was appropriate, but investigation of pretreatment clinical predictors of differential response, especially in 83 of the 136 psychotic patients, would be helpful to the clinician.

The favourable results suggest that, under realistic conditions, initial use of combined valproate and neuroleptics can be more effective than neuroleptics alone. This effect of valproate appears greater than in a previous report in which low dose carbamazepine added to haloperidol was beneficial, and carbamazepine has the disadvantage of lowering levels of haloperidol and other medications. ${ }^{4}$ A reciprocal strategy investigating the addition of neuroleptics or placebo in patients all treated with valproate would now be useful. The current results suggest that the 2 drugs may have synergistic effects. Their combined use may prompt rapid stabilisation with smooth transition to maintenance without neuroleptic treatment.

Alan C Swann, MD

University of Texas-Houston Medical School Houston, Texas, USA

1 Chou JC, Zito JM, Vitrai J, et al. Neuroleptics in acute mania: a pharmacoepidemiologic study. Ann Pharmacother 1996;30:1396-8.

2 Sernyak MJ, Godleski LS, Griffin RA, et al. Chronic neuroleptic exposure in bipolar outpatients. J Clin Psychiatry 1997;58:193-5.

3 McElroy SL, Keck PE, Stanton SP, et al. A randomized comparison of divalproex oral loading versus haloperidol in the initial treatment of acute psychotic mania.J Clin Psychiatry 1996;57:142-6.

4 Moller HJ, Kissling W, Riehl T, et al. Doubleblind evaluation of the antimanic properties of carbamazepine as a comedication to haloperidol. Prog Neuropsychopharmacol Biol Psychiatry 1989;13:127-36. 